\title{
Model Prototype Aplikasi Monitoring Tugas Akhir (MonTA) Mahasiswa pada STTI NIIT
}

\author{
Ristasari Dwi Septiana ${ }^{1}$, Fajar Septian ${ }^{2}$ \\ ${ }^{1}$ Teknik Informatika, STMIK Eresha, Tangerang Selatan, Indonesia \\ ${ }^{2}$ Teknik Informatika, Universitas Pamulang, Tangerang Selatan, Indonesia \\ e-mail: ${ }^{12}\{$ ristasari.dwis, fajarseptian45\}@ gmail.com
}

\begin{abstract}
Services for students' final tasks are very important to increase the number of graduates to be achieved by Universities. The problem faced is knowing the progress of the students' final task. The objective of this research was to build an application for monitoring the students' final task using a prototype model at STTI NIIT. The Prototype model in this research used to identify what services should be given to users. The collection of user needs is done by using the business model analysis technique to see the business processes that are occurring. Then build the prototype application model based on the requirements analysis. Function testing in this application is done by black-box testing, all of which functions can run well. Prototype this application can monitor the progress of students' final task. This application also can present consulting services for students' final task.
\end{abstract}

\section{Keywords: application, final task, monitoring, prototype model}

\section{Pendahuluan}

Pelayanan akademik yang baik sangat dibutuhkan oleh mahasiswa di setiap universitas atau sekolah tinggi, baik yang berkaitan dengan kegiatan akademik maupun non akademik. Dalam satu tahun ajaran terdapat mahasiswa yang mengajukan diri untuk melakukan penelitian tugas akhir, untuk itu dibutuhkan proses administrasi dan pengelolaan akademik yang baik. Administrasi tugas akhir mahasiswa di STTI NIIT belum bisa dilakukan secara sistem online mulai dari pengajuan proposal tugas akhir, menentukan dosen pembimbing, proses bimbingan, jadwal seminar metodologi dan jadwal sidang tugas akhir.

Masalah yang kerap kali terjadi adalah tidak adanya kesesuaian waktu yang dimiliki oleh mahasiswa dengan waktu kesediaan yang dimiliki oleh dosen pembimbing dalam melaksanakan bimbingan tugas akhir secara tatap muka sehingga intensitas proses bimbingan menjadi terhambat dan kurang maksimal. Masalah lainnya adalah waktu penyelesaian tugas akhir mahasiswa lebih dari satu semester bahkan terkadang bisa lebih dari dua semester untuk dapat mencapai ujian sidang tugas akhir.

Keberhasilan suatu tujuan ditentukan oleh fungsi perencanaan yang ditetapkan dan fungsi pengawasan atau monitoring yang berjalan dengan baik (Risnandar, 2015). Umumnya pihak manajemen universitas atau sekolah tinggi fokus terhadap kedua fungsi ini, yaitu fungi perencanaan dan fungsi pengawasan (monitoring). Adanya fungsi monitoring adalah untuk melihat seberapa tepat perencanaan kegiatan yang dijalankan agar tidak menyimpang dari jadwal yang disusun serta mengikuti perkembangan program yang dijalankan secara teratur dan terus-menerus.

Model prototype aplikasi monitoring tugas akhir mahasiswa (MonTA) manjadi salah satu bentuk pelayanan akademik yang dapat digunakan untuk mempermudah administrasi tugas akhir mahasiswa dan membantu mahasiswa dan dosen dalam pelaksanaan bimbingan tugas akhir, memeriksa judul tugas akhir yang diajukan oleh mahasiswa, penunjukan sebagai dosen pembimbing oleh ketua program studi, melihat kemajuan dokumen tugas akhir yang dikerjakan mahasiswa, membimbing mahasiswa dalam melaksanakan tugas akhir secara online, menyusun jadwal seminar metodologi, dan jadwal sidang tugas akhir.

\section{Penelitian Terkait}

Penelitian terkait yang pernah dilakukan peneliti lain digunakan untuk memberikan data yang lebih lengkap kepada peneliti. Selain itu peneliti gunakan sebagai komparasi dengan penelitian yang dilakukan agar mendapat hasil yang lebih baik. 
Penelitian Yudantoro, Triyono, Suyanto, Sulistyo, Mardiyono, Sakinah, dan Handoko (Yudantoro, et al., 2018) tugas akhir yang dilaksanakan di Prodi Teknik Informatika Politeknik Negeri Semarang melalui bebarapa proses dan proses tersebut masih dilakukan secara manual yang dianggap sangat tidak praktis. Hal tersebut mendorong diperlukannya sistem informasi manajemen tugas akhir untuk mempermudah administrasi tugas akhir, proses bimbingan sampai dengan sidang tugas akhir. Metode yang digunakan dalam membangun sistem informasi tersebut adalah waterfall. Sedangkan metode kuesioner digunakan untuk mengukur kepuasan pengguna. Hasil uji tingkat kepuasan mahasiswa, admin, dosen pembimbing, dosen penguji, sekretaris penguji dan kaprodi rata-rata sebesar $75 \%$.

Penelitian yang dilakukan Sulhan (Sulhan, 2015) menggunakan konsep User Generated Content (UGC) dengan sifat interaksi dua arah yang menghadirkan kolaborasi dan partisipasi untuk memberikan solusi pada sistem manajemen monitoring tugas akhir berbasis website di Prodi Sistem Informasi Universitas Kanjuruhan Malang. Hasil uji coba sistem ini semua fasilitas yang diberikan dapat berjalan dengan baik terutama konsep UGC yang diberikan sehingga penyelesaian tugas akhir dapat selesai tepat waktu.

Penelitian Ramayasa dan Arnawa (Ramayasa \& Arnawa, 2015) yang membahas monitoring progres pengerjaan skripsi di STMIK STIKOM Bali. Metode yang digunakan dalam membangun sistem tersebut dibagi dalam tiga proses besar, yakni (1) pengumpulan data, (2) analisis data, dan (3) menampilkan data. Data flow diagram digunakan sebagai alat perancangan. Hasil perancangan selanjutnya akan dibangun oleh tim pengembang yang hasilnya digunakan oleh dosen pembimbing, mahasiswa dan pihak admin.

Penelitian Prihatanto, Widada dan Laksito YS (Prihatanto, Widada, \& Laksito Y. S, 2015) membahas tentang pembuatan sistem monitoring tugas akhir di STMIK Sinar Nusantara. Masalah yang dibahas adalah karena selama ini pihak manajemen masih menggunakan software excel. Metode wawancara dan observasi digunakan untuk mengumpulkan data, sedangkan diagram konteks, DFD, HIPO digunakan sebagai alat perancangan sistem. Hasil penelitian ini berupa aplikasi sistem monitoring tugas akhir yang dapat berjalan dengan baik secara terkomputerisasi.

Penelitian yang dilakukan oleh Putra dan Arkan (Putra \& Arkan, 2017) dalam membuat sistem bimbingan tugas akhir mahasiswa di Universitas Bangka Belitung dengan pendekatan web server dan android. Kelebihan yang didapat dari pendekatan model ini adalah dosen dan mahasiswa akan mendapat notifikasi via smartphone android ketika ada dokumentasi tugas akhir yang diunggah oleh mahasiswa dan hasil review oleh dosen. Hasil pengujian sistem ini dapat memberikan informasi tentang progres pengerjaan tugas akhir secara real time, apakah dokumen tugas akhir sudah mendapat review oleh dosen pembimbing atau apakah mahasiswa sudah mengunggah dokumentasi tugas akhir untuk mendapat review dosen pembimbing pada smartphone berbasis android pengguna.

\section{Metode Penelitian}

Dalam penelitian ini metode yang dilakukan diawali dari tahap analisa sistem berjalan untuk pengumpulan data dengan melakukan kegiatan berikut:

a. Observasi

Teknik pengumpulan data dengan melakukan pengamatan langsung di kampus STTI NIIT, untuk mempelajari, mengamati, dan mengumpulkan informasi yang berhubungan dengan penelitian.

b. Wawancara

Melengkapi data yang sudah didapat selama observasi dengan pihak-pihak yang terkait. Tujuannya untuk memperdalam permasalahan serta sebagai dasar dalam perancangan pembuatan aplikasi.

c. Studi Pustaka

Menggunakan sumber-sumber yang ada di buku, jurnal, dan sumber bacaan penelitian terkait yang dapat mendukung penelitian ini.

Metode pengembangan aplikasi yang digunakan adalah model prototype. Model prototype digunakan untuk menghubungkan antara tidak paham pengguna dengan hal-hal yang bersifat teknis dan menspesifikasikan kebutuhan pengguna kepada pengembang perangkat lunak (Shalahuddin \& Rosa, 2015). 


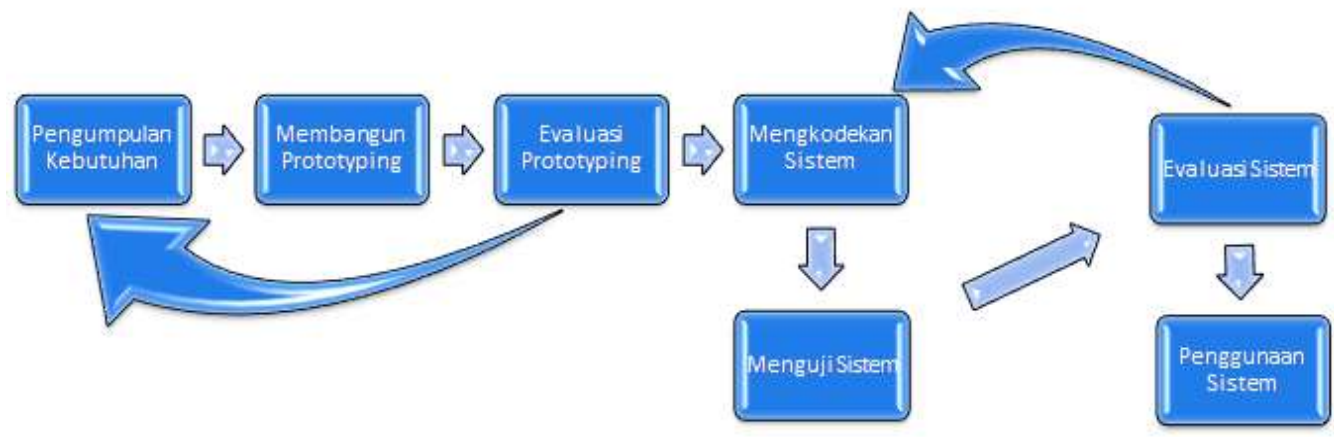

Gambar 1 Tahapan Model Prototype

Tahapan model prototype sebagai berikut:

1. Pengumpulan kebutuhan

Peneliti mendatangi calon pengguna aplikasi untuk mendapatkan fungsi apa saja yang diinginkan oleh calon pengguna terhadap aplikasi yang akan dibangun.

2. Membangun prototype

Peneliti menggunakan satu prototype untuk mengembangkan sebuah prototype aplikasi ini. Membangun prototype sementara yang fokus pada penyajian tampilan aplikasi yang diinginkan pengguna (misalnya format input dan output).

3. Evaluasi prototype

Evaluasi dilakukan oleh pengguna. Apakah prototype dibangun sesuai dengan keinginan pengguna? Jika sesuai maka lanjut ke langkah 4, jika tidak prototype direvisi dengan mengulangi langkah 1, 2, dan 3 .

4. Mengkodekan sistem

Pengkodean antarmuka sistem dilakukan menggunakan bahasa pemrograman PHP dan MySQL sebagai database management system.
5. Menguji sistem

Sebelum aplikasi digunakan harus diuji dahulu. Pengujian yang dilakukan dengan menggunakan black-box testing.

6. Evaluasi sistem

Evaluasi dilakukan untuk melihat apakah aplikasi sudah sesuai dengan spesifikasi awal. Langkah 7 akan dilakukan jika sudah sesuai, mengulangi langkah 4 dan 5 jika belum sesuai.

7. Penggunaan sistem

Aplikasi siap untuk digunakan jika telah lolos uji dan diterima pengguna.

\section{Hasil dan Pembahasan}

Hasil prototype aplikasi yang dibangun dapat dilihat pada rancangan basis data dan pemodelan sistem yang dilakukan dengan UML. Rancangan basis data aplikasi dalam bentuk LRS (Logical Record Structure) yang dibangun ditunjukan pada gambar 2 . 


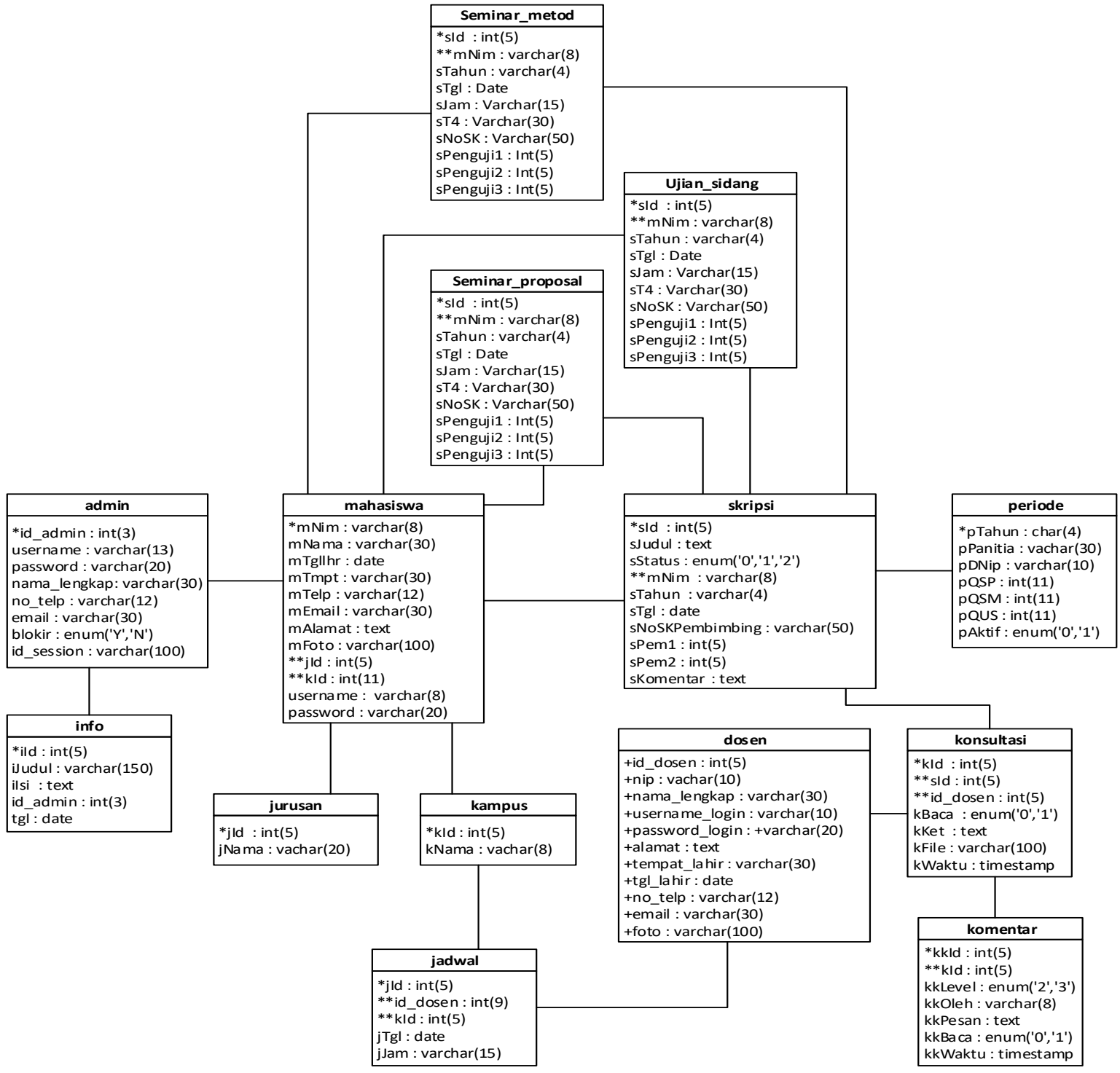

Gambar 2 Perancangan LRS Basis Data Aplikasi

UML (Unified Modelling Language) adalah alat pemodelan sistem atau perangkat lunak dengan paradigma berorientasi objek (Nugroho, 2010). Berdasarkan spesifikasi kebutuhan fungsional (proses) maka terdapat 16 use case dan 3 aktor dalam perancangan use case diagram aplikasi. Berikut adalah gambar use case diagram untuk aplikasi yang dibangun: 


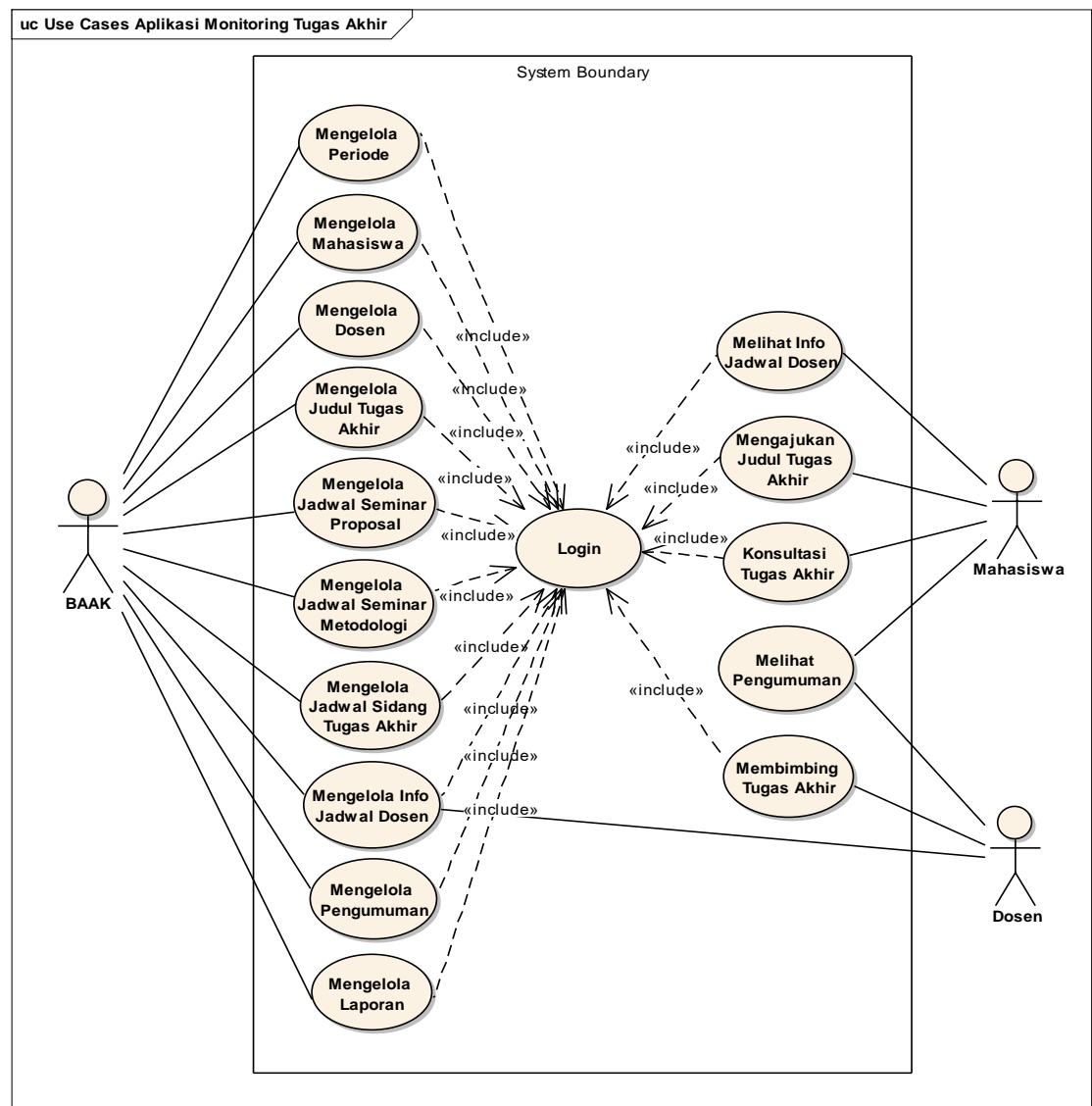

Gambar 3 Use Case Diagram Aplikasi

Implementasi antarmuka dimaksudkan untuk mengetahui siapa saja pengguna yang terlihat dalam aplikasi monitoring tugas akhir mahasiswa pada STTI NIIT. Ketika pengguna membuka aplikasi maka akan menuju ke halaman beranda yang terdiri atas menu beranda, menu tentang aplikasi dan menu pengumuman. Pada halaman beranda setiap pengguna dapat melakukan login untuk memulai aktifitas yang berhubungan dengan tugas akhir mahasiswa di dalam aplikasi. Halaman beranda dengan form login ditunjukan pada gambar 4 berikut.

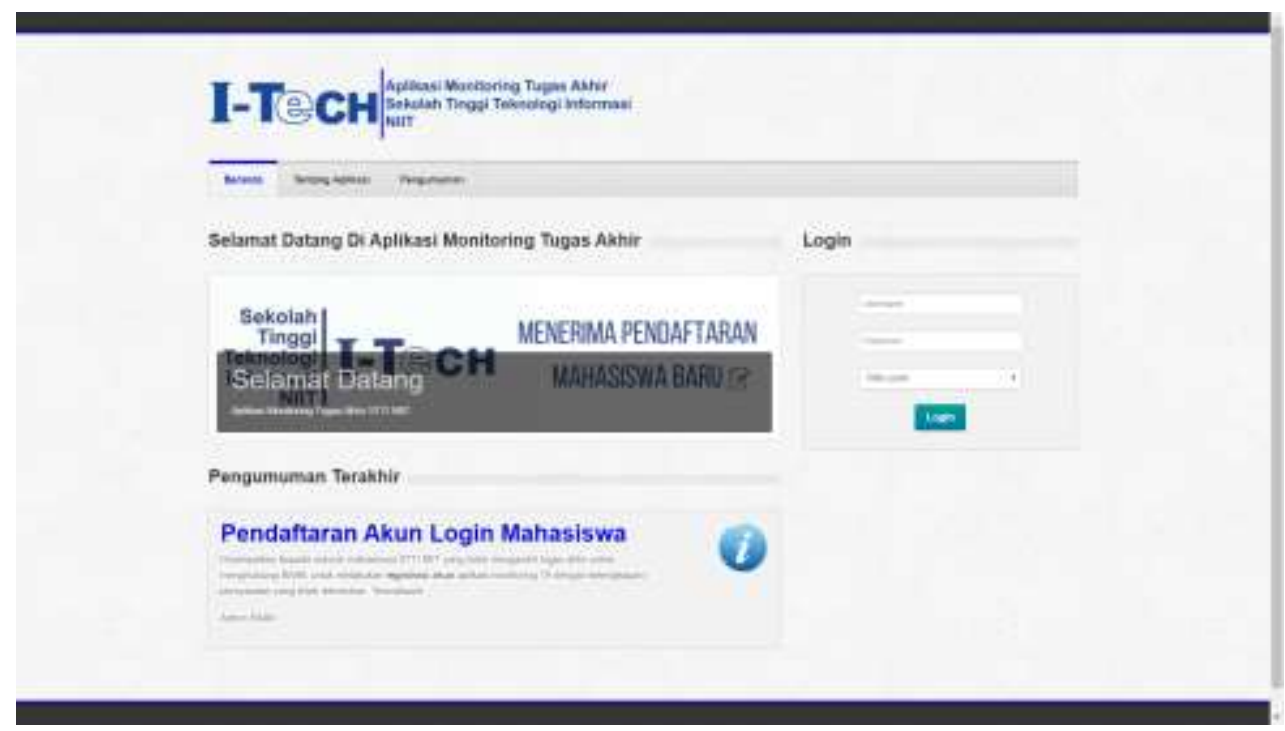

Gambar 4 Antarmuka Beranda dan Login Aplikasi 
Untuk dapat masuk ke dalam aplikasi pengguna harus memasukan username dan password yang benar pada form login. Jika belum memiliki username dan password, pengguna harus mendaftar ke Bagian Administrasi Akademik dan Kemahasiswaan (BAAK) sebagai admin aplikasi.
Setelah proses login selesai maka pengguna dengan level akses mahasiswa langsung dapat mengajukan judul tugas akhir melalui form input judul. Gambar 5 adalah halaman antarmuka untuk mengajukan judul tugas akhir mahasiswa.

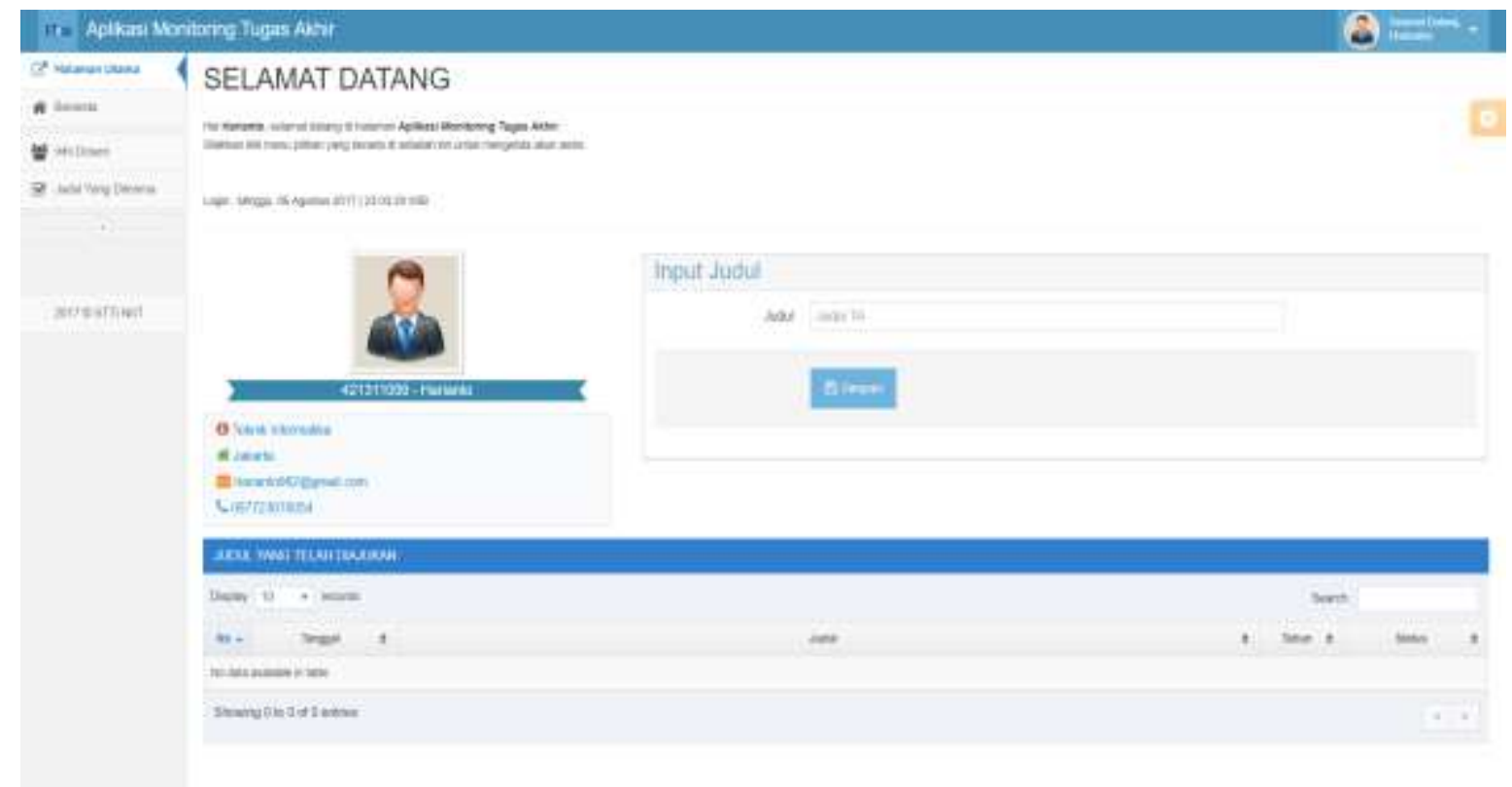

Gambar 5 Antarmuka Mengajukan Judul Tugas Akhir

Pada gambar 5 di atas terdapat komponen identitas mahasiswa berupa foto, nomor induk mahasiswa, nama, jurusan, alamat, surat elektronik dan nomor telepon. Komponen lainnya adalah form input judul dan grid untuk judul yang diajukan dan dilengkapi dengan status judul. Jika mahasiswa sudah mengajukan judul tugas akhir melalui aplikasi ini, maka mahasiswa akan mendapatkan pesan untuk menunggu verifikasi dari bagian BAAK tentang judul yang diajukan yang nantinya terlihat pada grid judul yang diajukan dengan status diterima atau ditolak. Jika judul diterima maka selanjutnya mahasiswa dapat melakukan konsultasi via aplikasi ini. Gambar 6 adalah halaman antarmuka untuk konsultasi tugas akhir.

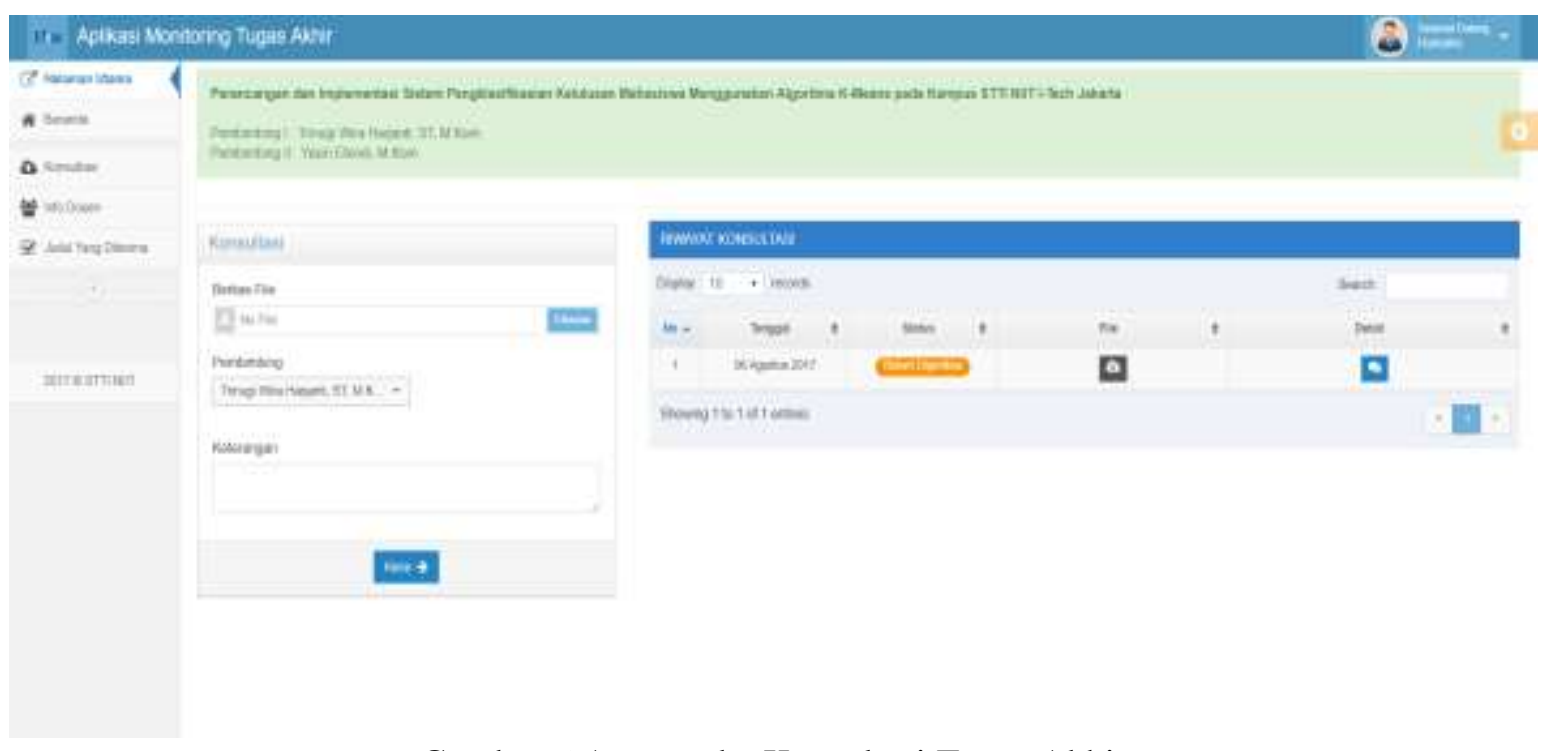

Gambar 6 Antarmuka Konsultasi Tugas Akhir 
Pada gambar 6 di atas, mahasiswa dapat melakukan konsultasi tugas akhir via aplikasi dengan cara input form konsultasi dan mengunggah file yang akan dikonsultasikan ke pembimbing, dan keterangan konsultasi. Semua konsultasi mahasiswa ditampung di dalam tabel riwayat konsultasi lengkap dengan detail percakapan konsultasi.

Pengujian yang dilakukan pada aplikasi ini adalah black-box testing yang berfokus pada fungsi program. Spesification testing atau black-box testing yang melakukan verifikasi perilaku unit pengujian yang tampak dari luar (Nugroho, 2010). Black-box testing adalah pengujian yang berfokus pada spesifikasi fungsional dari perangkat lunak tanpa menguji desain dan kode program (Shalahuddin \& Rosa, 2015). Hasil pengujian black-box testing aplikasi ini ditujukan pada tabel berikut:

Tabel 1 Hasil Black-Box Testing Antarmuka Mengajukan Judul Tugas Akhir

\begin{tabular}{|l|l|l|c|}
\hline \multicolumn{1}{|c|}{ Deskripsi } & \multicolumn{1}{c|}{ Hasil yang Diharapkan } & \multicolumn{1}{c|}{ Hasil Pengujian } & Kesimpulan \\
\hline $\begin{array}{l}\text { Mahasiswa mengisi } \\
\text { judul pada form input } \\
\text { judul tugas akhir dan } \\
\text { klik tombol simpan. }\end{array}$ & $\begin{array}{l}\text { Aplikasi akan menyimpan data } \\
\text { judul lalu menampilkan pesan } \\
\text { "data berhasil disimpan" dan } \\
\text { data judul akan muncul pada } \\
\text { grid judul yang diajukan. }\end{array}$ & $\begin{array}{l}\text { Aplikasi berhasil } \\
\text { menyimpan judul lalu } \\
\text { menampilkan pesan "data } \\
\text { berhasil disimpan" dan } \\
\text { data judul muncul pada } \\
\text { grid judul yang diajukan. }\end{array}$ & Diterima \\
\hline $\begin{array}{l}\text { Mahasiswa } \\
\text { mengosongkan form } \\
\begin{array}{l}\text { input judul tugas akhir } \\
\text { dan klik tombol simpan. }\end{array}\end{array}$ & $\begin{array}{l}\text { Aplikasi akan gagal } \\
\text { menyimpan data judul lalu } \\
\text { menampilkan pesan "judul } \\
\text { harus diisi". }\end{array}$ & $\begin{array}{l}\text { Aplikasi gagal menyimpan } \\
\text { data lalu menampilkan } \\
\text { pesan "judul harus diisi". }\end{array}$ & Diterima \\
\hline
\end{tabular}

Tabel 2 Hasil Pengujian Antarmuka Konsultasi Tugas Akhir

\begin{tabular}{|l|l|l|c|}
\hline \multicolumn{1}{|c|}{ Deskripsi } & \multicolumn{1}{c|}{ Hasil yang Diharapkan } & \multicolumn{1}{c|}{ Hasil Pengujian } & Kesimpulan \\
\hline $\begin{array}{l}\text { Mahasiswa mengisi } \\
\text { form input data } \\
\text { konsultasi dan klik } \\
\text { tombol kirim. }\end{array}$ & $\begin{array}{l}\text { Aplikasi akan menyimpan data } \\
\text { konsultasi lalu menampilkan } \\
\text { pesan "data berhasil disimpan" } \\
\text { dan data konsultasi akan } \\
\text { muncul pada grid riwayat } \\
\text { konsultasi. }\end{array}$ & $\begin{array}{l}\text { Aplikasi berhasil } \\
\text { menyimpan data konsultasi } \\
\text { lalu menampilkan pesan } \\
\text { "data berhasil disimpan" } \\
\text { dan data konsultasi muncul } \\
\text { pada grid riwayat } \\
\text { konsultasi. }\end{array}$ & Diterima \\
\hline $\begin{array}{l}\text { Mahasiswa } \\
\text { mengosongkan form } \\
\text { input data konsultasi dan } \\
\text { klik tombol kirim. }\end{array}$ & $\begin{array}{l}\text { Aplikasi akan gagal } \\
\text { menyimpan data konsultasi } \\
\text { lalu menampilkan pesan "data } \\
\text { konsultasi harus diisi". }\end{array}$ & $\begin{array}{l}\text { Aplikasi gagal menyimpan } \\
\text { data lalu menampilkan } \\
\text { pesan "data konsultasi } \\
\text { harus diisi". }\end{array}$ & Diterima \\
$\begin{array}{l}\text { Mahasiswa klik icon } \\
\text { unduh file konsultasi } \\
\text { tugas akhir. }\end{array}$ & $\begin{array}{l}\text { Aplikasi akan mengunduh file } \\
\text { konsultasi tugas akhir. }\end{array}$ & $\begin{array}{l}\text { Aplikasi berhasil } \\
\text { mengunduh file konsultasi } \\
\text { tugas akhir. }\end{array}$ & Diterima \\
\hline $\begin{array}{l}\text { Mahasiswa klik } \text { icon } \\
\text { detail konsultasi. }\end{array}$ & $\begin{array}{l}\text { Aplikasi akan menampilkan } \\
\text { halaman detail konsultasi } \\
\text { tugas akhir. }\end{array}$ & $\begin{array}{l}\text { Aplikasi berhasil } \\
\text { menampilkan halaman } \\
\text { detail konsultasi tugas } \\
\text { akhir. }\end{array}$ & Diterima \\
\hline
\end{tabular}

\section{Kesimpulan}

Kesimpulan yang didapat dari penelitian ini adalah (a) Dihasilkan model prototype aplikasi monitoring tugas akhir mahasiswa yang memberikan fitur pengajuan judul tugas akhir, konsultasi online, informasi jadwal seminar proposal, jadwal seminar metodologi, jadwal sidang tugas akhir, cetak surat tugas, cetak lembar konsultasi dan unggah file tugas akhir; (b) Hasil pengujian secara black box testing menunjukkan semua fitur dapat berjalan dengan baik sesuai dengan spesifikasi pengguna; dan (c) Pihak kampus dapat melakukan monitoring progres mahasiswa yang sedang melaksanakan tugas akhir dengan adanya fitur konsultasi online antara dosen dan mahasiswa. 


\section{Referensi}

Nugroho, A. (2010). Rekayasa Perangkat Lunak Berorientasi Objek dengan Metode USDP. Yogyakarta: Andi Offset.

Prihatanto, R. H., Widada, B., \& Laksito Y. S, W. (2015). Sistem Monitoring Pembimbingan Tugas Akhir Di STMIK Sinar Nusantara Surakarta. Jurnal TIKomSiN, 03(02), 57-65.

Putra, G. B., \& Arkan, F. (2017). Implementasi Sistem Bimbingan Tugas Akhir Mahasiswa Berbasis Web Server Dan Android. Seminar Nasional Vokasi dan Teknologi (SEMNASVOKTEK) (pp. 137-145). Bali: Universitas Pendidikan Ganesha.

Ramayasa, I. P., \& Arnawa, I. B. (2015). Perancangan Sistem Monitoring Pengerjaan Skripsi Pada Stmik Stikom Bali Berbasis Web. Konferensi Nasional Sistem \& Informatika (pp. 760-765). Bali: STMIK STIKOM.
Risnandar, E. (2015). Pembuatan Aplikasi Sistem Informasi Monitoring Kegiatan Mahasiswa Berbasis Web dan Android Client. Semarang: Universitas Negeri Semarang.

Shalahuddin, M., \& Rosa, A. S. (2015). Modul Pembelajaran Rekayasa Perangkat Lunak (Terstruktur dan Berorientasi Objek). Bandung: Modula.

Sulhan, M. (2015). Sistem Monitoring Tugas Akhir Berbasis User Generated Content Pada Program Studi Sistem Informasi Universitas Kanjuruhan Malang. SMATIKA Jurnal, 05(02), 58-68.

Yudantoro, T. R., Triyono, L., Suyanto, B., Sulistyo, W., Mardiyono, Sakinah, A. N., \& Handoko, S. (2018). Sistem Informasi Monitoring Tugas Akhir Mahasiswa Prodi Teknik Informatika Polines. Prosiding SINTAK (pp. 295-305). Semarang: Universitas Stikubang. 